\title{
Exogenous transforming growth factor- $\beta 1$ prevents the inflow of fluoride to ameleoblasts through regulation of voltage-gated chloride channels 5 and 7
}

\author{
MEI JI, XUEJING DUAN，XIAOHUI HAN，JING SUN and DONGSHENG ZHANG \\ Department of Stomatology, Shandong Provincial Hospital Affiliated to Shandong University, \\ Jinan, Shandong 250021, P.R. China
}

Received March 22, 2020; Accepted March 15, 2021

DOI: $10.3892 /$ etm.2021.10047

\begin{abstract}
Dental fluorosis is a global issue. Although there are multiple causes of dental fluorosis, the precise mechanism remains controversial. Previous studies have demonstrated that extracellular fluoride may promote an accumulation of fluoride ions in ameloblasts, which may induce oxidative and endoplasmic reticulum stresses, leading to dental fluorosis. However, the exact process by which fluoride ions enter cells has not been determined. In the present study, intracellular fluoride concentration was determined using a newly developed specific fluorescent probe called probe 1 . Under high extracellular fluoride concentrations, the fluorescence intensity of the ameloblasts increased, however, exogenous transforming growth factor- $\beta 1$ (TGF- $\beta 1$ ) was able to inhibit the increase. Furthermore, changes in the expression of the voltage-gated chloride channels 5 and 7 (ClC5 and $\mathrm{ClC}-7$ ), which are responsible for the transport of fluoride were investigated. The results indicated that fluoride reduced the expression of endogenous TGF- $\beta 1$ and increased the expression of $\mathrm{ClC}-5$ and $\mathrm{ClC}-7$. Additionally, exogenous TGF- $\beta 1$ reduced the expression of $\mathrm{ClC}-5$ and $\mathrm{ClC}-7$. The results of the present study indicate that exogenous TGF- $\beta 1$ may prevent accumulation of fluoride in
\end{abstract}

Correspondence to: Professor Dongsheng Zhang, Department of Stomatology, Shandong Provincial Hospital Affiliated to Shandong University, 324 Jingwu Road, Jinan, Shandong 250021, P.R. China

E-mail: ds63zhang@sdu.edu.cn

Abbreviations: ClC-5, voltage-gated chloride channel 5; ClC-7, voltage-gated chloride channel 7; CICs, voltage-gated chloride channels; CFTR, cystic fibrosis transmembrane conductance regulator; CLCA, calcium-activated chloride channels; CLICs, chloride intracellular channels; ECM, extracellular matrix; HA, hydroxyapatite; HF, hydrogen fluoride; KLK4, kallikrein 4; LS8, the ameloblast-like cell line; RT-qPCR, reverse transcription-quantitative PCR; TGF- $\beta 1$, transforming growth factor- $\beta 1$

Key words: fluoride, chloride channels, transforming growth factor- $\beta 1$, ameloblasts, probe ameloblasts through the regulation of ClC-5 and ClC-7 under high extracellular fluoride concentrations.

\section{Introduction}

The supplementation of drinking water with fluoride is an established method to prevent dental caries (1). According to the Dean index, the optimal concentration of fluoride in drinking water is $1 \mathrm{ppm}$ (2). Nevertheless, in In many areas of the world, the natural fluoride levels in drinking water exceed the recommended concentration (1). In some areas, the natural fluoride levels in drinking water are extremely high, such as in Colorado (11.2 mg/l), Oklahoma (12.0 mg/l), New Mexico (13.0 mg/l) and Idaho (15.9 mg/l) (3). With the development of dentistry, fluoride has also been added to dental materials, including toothpaste, varnish, foam and dental resin, to prevent the occurrence of caries. All these fluoride additions increase the morbidity of dental fluorosis (3), which is currently a worldwide problem. A small 'pea-sized' amount of toothpaste would contain $0.36-0.72 \mathrm{mg}$ fluoride, which would increase the risk of dental fluorosis in children (4). In America, the prevalence of dental fluorosis in children aged 15-17 years increased from $22.6 \%$ in the $1986-1987$ to $40.6 \%$ in the $1999-2004$, which was provided by the National Health and Nutrition Examination Survey (5). Although there are multiple causes of dental fluorosis, the precise mechanism remains controversial $(6,7)$. The regulation of intracellular and extracellular $\mathrm{pH}$ is an important mechanism that may lead to dental fluorosis. According to the acid hypothesis (8), fluoride ions are unable to enter the cell, whereas hydrogen fluoride (HF) can readily cross the cell membrane under acidic conditions (9). An increased fluoride concentration in the cytoplasm may induce oxidative stress by reducing the activity of antioxidant enzymes, thereby affecting a variety of structures and processes of normal cells due to reactive oxygen species accumulation $(8,10-12)$. Furthermore, fluoride in the cytoplasm may induce endoplasmic reticulum (ER) stress, including the phosphorylation of the eukaryotic initiation factor 2 (eIF2), which may result in a decrease in the overall protein production, including secretion of the protease kallikrein 4 (KLK4) (8,13-15). However, studies on fluoride transport have primarily used fibroblasts and epithelial cells from the rat stomach and urinary bladder, 
hamster cheek pouch and renal tubules of several species, and very little research has been carried out in ameloblasts $(9,16)$. Sharma et al (13) reported that a low $\mathrm{pH}$ environment in the maturation stage of ameloblasts facilitated the uptake of fluoride. This hypothesis was tested by measuring changes in stress-related genes and proteins. Fluorescent probes are a more intuitive method to observe the accumulation of fluoride in ameloblasts (17). However, limitations remain in the majority of the reported fluorescent fluoride probes in terms of determination and bioimaging (17-20). For example, pyrene-based dye lies within the ultraviolet-visible light range, increasing the difficulties in targeting fluoride in living animals $(17,18)$. Although the probes with the lipophilic TBDPS moiety have high selectivity, their performance in apparent optical signal changes to the naked-eye remains poor $(17,19,20)$. To improve on these methods, a highly selective ratiometric visual and red-emitting fluorescent dual-channel, probe 1, was developed. The probe contains the hydrophilic compound 2-dicyanomethylene-3-cyano-4,5,5-trimethyl-2,5-dihydrofuran (TCF) and the lipophilic tert-butyldiphenylsilyl (TBDPS); therefore, it can enter cells easily $(21,22)$. Additionally, probe 1 possesses a latent internal charge transfer structure, which makes it detect signals to the naked-eye $(21,22)$. Through cleavage of the $\mathrm{Si}-\mathrm{O}$ bond, fluoride transforms probe 1 into a red-emitting fluorescent form. Therefore, probe 1 reflects the distribution of the fluoride ion may be used to determine fluoride concentration $(17,21,22)$.

The epithelial transport process of fluoride relies on ion channels. To the best of our knowledge, no specialized fluoride channels have been identified. It is generally accepted that fluoride ions pass through the membrane via chloride channels (23). There are differences in the permeability and conductivity of fluoride between different chloride channels (23). Simchowitz (24). found that human neutrophils were selective for haloid ions, and the order of affinity for these ions was $\mathrm{Cl}>\mathrm{Br}>\mathrm{F}>\mathrm{I}^{-}$, which were reverse-transported in a 1:1 ratio to extracellular $\mathrm{Cl}^{-}$. Studies on the epithelium of the respiratory tract have revealed that its chloride channels are highly selective for anions and that their ionic permeability to halogens is in the order of $\mathrm{I}>\mathrm{Br} \geq \mathrm{Cl}>\mathrm{F}^{-}(25,26)$. Additionally, Anderson et al (27) demonstrated that the order of selectivity of cystic fibrosis transcription factor for anions was $\mathrm{Br}>\mathrm{Cl}>\mathrm{I}>\mathrm{F}^{-}$. In mammals, several classes of chloride channels have been found, including voltage-gated chloride channels (ClCs), the cystic fibrosis transmembrane conductance regulator (CFTR), calcium-activated chloride channels (CLCAs) and chloride intracellular channels (CLICs) (28). There are nine $\mathrm{ClCs}$, namely $\mathrm{ClC}-1$ to $\mathrm{ClC}-7$, $\mathrm{ClC}-\mathrm{Ka}$, and $\mathrm{ClC}-\mathrm{Kb}$. $\mathrm{ClCs}-3-7$ function as the main $\mathrm{Cl}^{-} / \mathrm{H}^{+}$-exchangers, and facilitate vesicular acidification by shunting currents of proton pumps and by increasing vesicular $\mathrm{Cl}^{-}$concentration $(29,30)$. ClCs control the electrical excitability of muscles or neurons, extra- and intracellular ion homeostasis and transepithelial transport (30). Hou et al (31) found that $\mathrm{ClCs}-1-7$ were expressed in tooth germs. ClC-5 has been reported in the dental lamina, inner enamel epithelium, stratum intermedium, outer enamel epithelium, odontoblasts and ameloblasts (32). CLCN7 mRNA has been reported in ameloblasts at the maturation-stage (33). CFTR plays an important role in transportation of bicarbonate into the enamel space to buffer protons in ameloblasts and is located on the apical plasma membrane during the maturation stage of ameloblasts (34). Lacruz et al (35) reported that the mRNA level of CFTR in rat ameloblasts was higher at the early-mid and mid-late maturation stages than at the secretory stage. Furthermore, previous studies have indicated that CFTR is a critical factor in the regulation of $\mathrm{pH}$ during the maturation of ameloblasts and is essential for enamel mineralization $(34,36,37)$. Duan et al (38) demonstrated that CFTR inhibition and treatment with CFTR siRNA may increase intracellular $\mathrm{pH}$. In our previous study, $\mathrm{ClC}-5$ and $\mathrm{ClC}-7$, which are $\mathrm{Cl}^{-} / \mathrm{H}^{+}$-exchangers related to tooth development and $\mathrm{pH}$ regulation were the focus (30).

As a member of the transforming growth factor- $\beta$ (TGF- $\beta$ ) superfamily, TGF- $\beta 1$ regulates cellular biological processes, such as proliferation, differentiation, apoptosis and extracellular matrix (ECM) protein production (39). Furthermore, it plays an important role in tooth development $(32,40)$. Duan et al (32) indicated that $\mathrm{ClC}-5$ regulates dentine development through the TGF- $\beta 1$ pathway. Previous studies have revealed that fluoride affects enamel protein content via TGF- $\beta 1$-mediated KLK4 inhibition $(41,42)$. TGF- $\beta 1$ may also impair the expression and function of chloride ion channels in other epithelial cells, including alveolar, bronchial, vas deferens and nasal polyp epithelial cells (43-46). However, whether the expression and function of chloride ion channels in ameloblasts is regulated by TGF- $\beta 1$ remains to be elucidated.

In the present study the correlation between TGF- $\beta 1$ and the intracellular fluoride concentration at a high extracellular fluoride concentration was investigated. Furthermore, the effects of exogenous TGF- $\beta 1$ on ClC-5 and ClC-7 under a high extracellular fluoride concentration were studied.

\section{Materials and methods}

Cell culture. The ameloblast-like cell line (LS8) was a gift from Prof. Malcolm L. Snead (University of Southern California, USA), and was cultured in DMEM (Corning, Inc.) supplemented with $10 \%$ fetal bovine serum (FBS; Biological Industries) and antibiotics (100 U/ml of penicillin and $100 \mu \mathrm{g} / \mathrm{ml}$ of streptomycin; Gibco; Thermo Fisher Scientific, Inc.). The cells were incubated at $37^{\circ} \mathrm{C}$ in a $5 \% \mathrm{CO}_{2}$ incubator and the medium was replaced with fresh medium every 2 days. The experiments were performed in triplicate.

Reverse transcription-quantitative PCR (RT-qPCR). The following groups of ameloblast-like LS8 cells were established: Control; high fluoride, treated with a high fluoride concentration (2.0 mM F-;Sigma-Aldrich; Merck KGaA); TGF- $\beta 1$, treated with $10 \mathrm{ng} / \mathrm{ml} \mathrm{TGF- \beta 1} \mathrm{(Peprotech} \mathrm{Inc.);} \mathrm{and} \mathrm{FT,} \mathrm{treated}$ with $2.0 \mathrm{mM} \mathrm{F}^{-}+10 \mathrm{ng} / \mathrm{ml}$ TGF- $\beta 1$. Cells were plated into six-well plates at a density of $1 \times 10^{6}$ cells $/ \mathrm{ml}$ and treated with different conditions as aforementioned for $24 \mathrm{~h}$. Total RNA of different groups were extracted using RNAiso (Takara Bio, Inc.) according to the manufacturer's instructions. cDNA was synthesized using the PrimeScript ${ }^{\mathrm{TM}}$ RT reagent kit with gDNA Eraser using the temperature protocols of $37^{\circ} \mathrm{C}$ for $15 \mathrm{~min}$ and $85^{\circ} \mathrm{C}$ for $5 \mathrm{sec}$ (Takara, Bio. Inc.). Mouse-specific primers for GAPDH (47), TGF- $\beta 1, \mathrm{ClC}-5$ and ClC-7, were used in conjunction with SYBR Premix Ex Taq ${ }^{\mathrm{TM}}$ II (Takara Bio., Inc.) for RNA measurement. All qPCR reactions were conducted under 
Table I. Primer sequences for reverse transcription-quantitative PCR.

\begin{tabular}{lll}
\hline Gene & \multicolumn{1}{c}{ Forward sequence $\left(5^{\prime}-3^{\prime}\right)$} & \multicolumn{1}{c}{ Reverse sequence 5'-3' } \\
\hline TGF- $\beta 1$ & CTTCAATACGTCAGACATTCGGG & GTAACGCCAGGAATTGTTGCTA \\
ClC-5 & GAGGAGCCAATCCCTGGTGTA & TTGGTAATCTCTCGGTGCCTA \\
ClC-7 & CGCCAGTCTCATTCTGCACT & GAGGATCGACTTCCGGGTC \\
GAPDH & TGACCTCAACTACATGGTCTACA & CTTCCCATTCTCGGCCTTG \\
\hline
\end{tabular}

TGF- $\beta 1$, transforming growth factor- $\beta 1$; ClC-5, voltage-gated chloride channel 5; ClC-7, voltage-gated chloride channel 7.

the following conditions: Hot start for $30 \mathrm{sec}$ at $95^{\circ} \mathrm{C}$, followed by 40 cycles of $5 \mathrm{sec}$ at $95^{\circ} \mathrm{C}$ and $30 \mathrm{sec}$ at $60^{\circ} \mathrm{C}$. The primer sequences used are presented in Table I. In the next step, the target mRNA expression levels were determined using the LightCycler 480 Real-Time PCR System (Roche Diagnostics). The relative expression of target genes was calculated using the $2^{-\Delta \Delta \mathrm{Cq}}$ method (48). Each group was set with three repeated wells and their mean values were calculated.

Western blot analysis. Total protein was extracted from $60 \mathrm{~mm}$ dishes (Corning, Inc.) containing the ameloblast-like LS8 cells with the seeding density of $2 \times 10^{6}$ cells $/ \mathrm{ml}$ and treated as described in the previous section. The protein concentration of each sample was determined with a bicinchoninic acid assay (Beijing Solar Bio Science \& Technology Co., Ltd.). To separate TGF- $\beta 1, \mathrm{ClC}-5$ and $\mathrm{ClC}-7$, equal amounts of proteins $(40 \mu \mathrm{g})$ were loaded onto $10 \%$ SDS-PAGE gels and then the proteins were transferred onto PVDF membranes. Membranes were blocked in Tris-buffered saline Tween (hereafter called TBST) with $1 \%$ Tween and 5\% non-fat dry milk for $1 \mathrm{~h}$ at room temperature and the membranes were labelled with antibodies against TGF- $\beta 1, \mathrm{ClC}-5$ and $\mathrm{ClC}-7$ at $4{ }^{\circ} \mathrm{C}$ overnight. The probed membranes were washed with TBST three times and incubated with appropriate secondary antibodies for $1 \mathrm{~h}$ at room temperature. Protein bands were visualised using the enhanced chemiluminescence (ECL, Thermo Fisher Scientific, Inc.) detection system Amersham Imager 600 (GE Healthcare; Cytiva). The primary antibodies used were all rabbit-derived and were anti-GAPDH at a ratio of 1:500 (cat. no. BA2913; Wuhan Boster Biological Technology Co., Ltd.), anti-TGF- $\beta 1$ at a ratio of 1:1,000 (cat. no. ab92486; Abcam), anti-ClC-5 at a ratio of 1:1,000 (cat. no. ab188503; Abcam), anti-ClC-7 at a ratio of 1:1,000 (cat. no. ab136016; Abcam). Secondary antibodies used were horseradish peroxidase-labelled-goat-derived anti-rabbit at a ratio of 1:5,000 (cat. no. BA1054; Wuhan Boster Biological Technology Co., Ltd.) and horseradish peroxidase-labelled rabbit-derived anti-goat at a ratio of 1:5,000 (cat. no. BA1060; Wuhan Boster Biological Technology Co., Ltd.).

Intracellular fluoride detection through confocal laser scanning microscopy. LS8 cells were seeded into $35 \mathrm{~mm}$ glass bottom dishes (cat. no. P35G-1.5-14-C; MatTek Corporation) at a density of $4 \times 10^{5}$ cells/dish. After adhesion, cells were treated for $24 \mathrm{~h}$, as described for RT-qPCR, before $10 \mu \mathrm{l}$ the probe 1 was added to each dish and the dishes maintained at room temperature for $30 \mathrm{~min}$ (49). The emitted fluorescence intensity was determined using a confocal laser scanning microscope (model no. LSM 780; Zeiss AG) at $543 \mathrm{~nm}$. The mean fluorescence intensities were calculated by ImageJ $1.52 \mathrm{v}$. Probe 1 was provided by Professor Baocun Zhu (Jinan University, Shandong, China).

Statistical analysis. All values are presented as the mean \pm the standard deviation (SD). Western blot and RT-qPCR results were analysed by one-way ANOVA. Multiple comparisons between groups were performed using the Tukey's test. $\mathrm{P}<0.05$ was considered statistically significant and $\mathrm{P}<0.01$ values was considered highly statistically significant.

\section{Results}

Fluoride treatment reduces TGF- $\beta 1$ expression in LS8 cells. Fig. 1A indicates the relative value (compared with the internal reference GAPDH) of TGF- $\beta 1$ mRNA expression. In the samples from the high fluoride group, endogenous TGF- $\beta 1$ mRNA expression levels were significantly lower than those of the control group. Fig. 1B indicates the relative value (compared with the internal reference GAPDH) of TGF- $\beta 1$ protein expression. Consistent with the RT-qPCR results, endogenous TGF- $\beta 1$ protein expression in the high fluoride group was significantly lower than that of the control group.

Fluoride increases the expression levels of $\mathrm{ClC}-5$ and $\mathrm{ClC}-7$ in LS8 cells. Fig. 2A indicates the relative values (compared with the internal reference GAPDH) of ClC-5 and ClC-7 mRNA expression levels. In the high fluoride group, ClC-5 and ClC-7 mRNA expression levels were significantly higher than those of the control group. Fig. 2B indicates the relative values (compared with the internal reference GAPDH) of $\mathrm{ClC}-5$ and ClC-7 protein expression. ClC-5 protein expression in the high fluoride group was significantly higher than that in the control group. $\mathrm{ClC}-7$ protein expression in the high fluoride group was higher than that in the control group.

Exogenous TGF- $\beta 1$ reduces the expression of $\mathrm{ClC}-5$ and $\mathrm{ClC}-7$ in LS8 cells. Fig. 3A illustrates the relative values (compared with the internal reference GAPDH) of ClC-5 and ClC-7 mRNA expression levels. In the high fluoride group the $\mathrm{ClC}-5$ and ClC-7 mRNA expression levels were significantly higher than those of the control group. In the exogenous TGF- $\beta 1$ group, ClC-5 and ClC-7 mRNA expression levels were significantly lower than those of the control group. In the FT group, ClC-5 and ClC-7 mRNA expression levels were significantly lower 


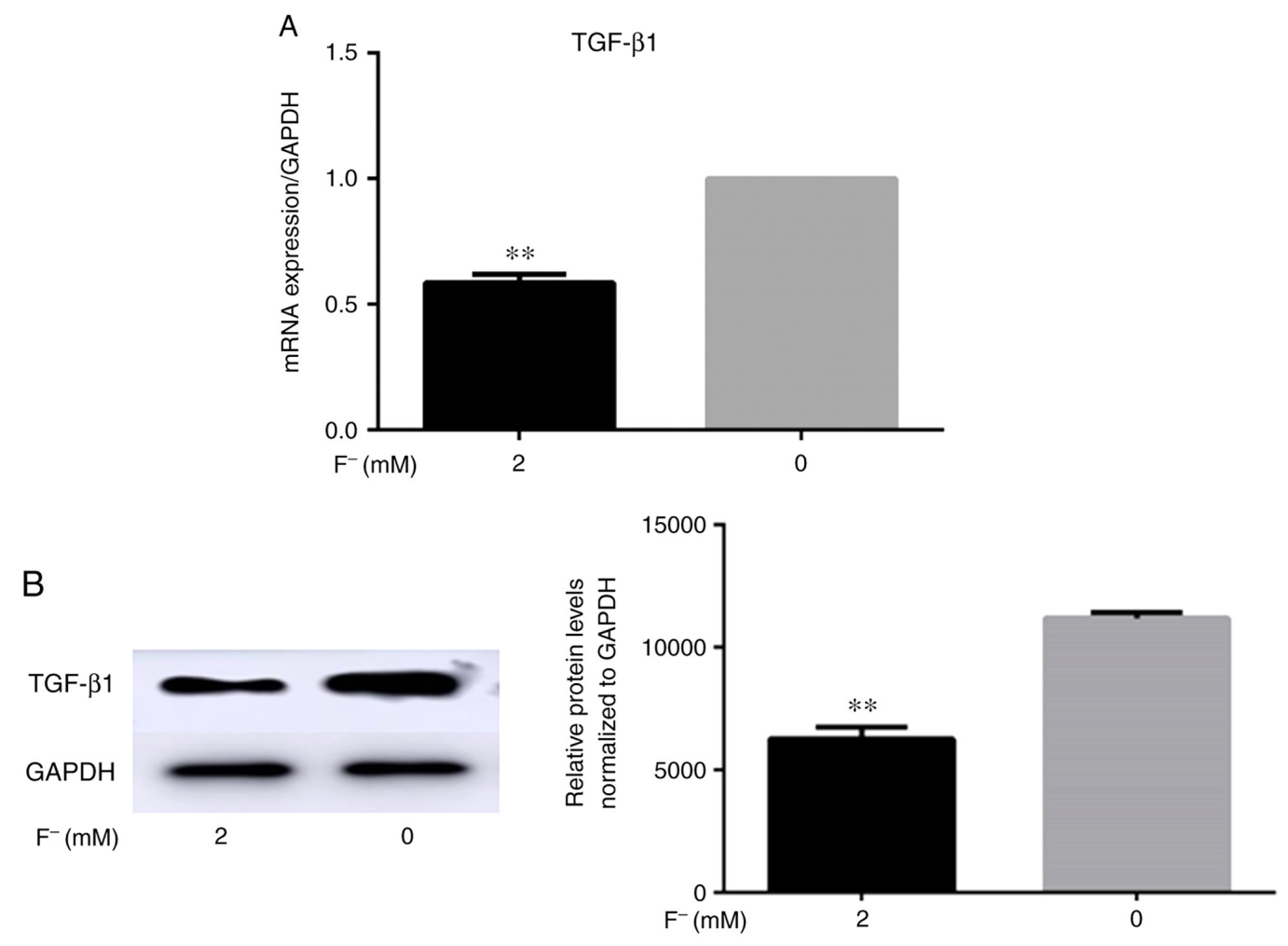

Figure 1. Effect of high fluoride on the TGF- $\beta 1$ expression in ameloblasts. (A) TGF-mRNA levels and (B) TGF-protein levels were determined in control and high fluoride treated cells. Data are presented as the mean \pm the standard deviation of three repeated experiments. ${ }^{* * *} \mathrm{P}<0.01 \mathrm{vs}$. control. TGF- $\beta 1$, transforming growth factor- $\beta 1$.

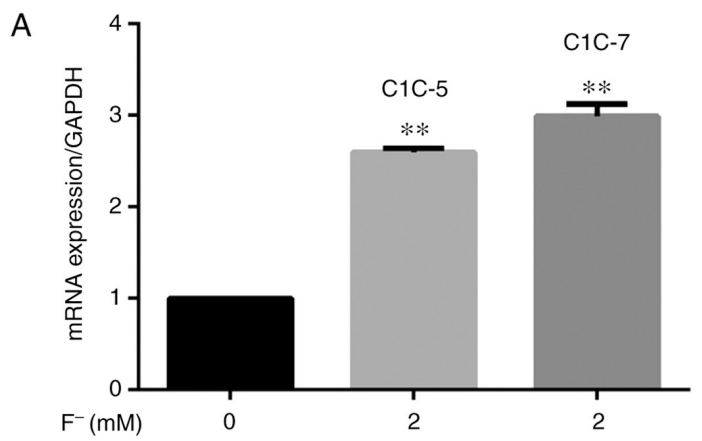

B
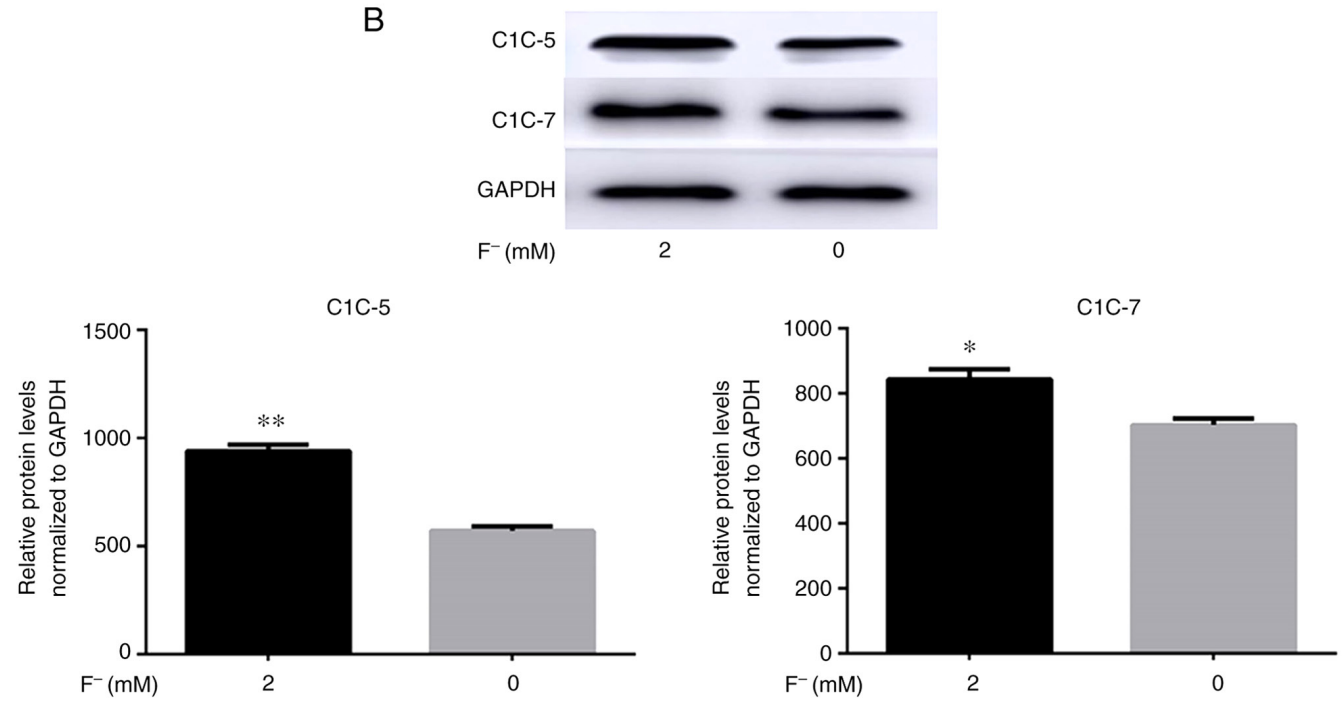

Figure 2. Effects of high fluoride on ClC-5 and ClC-7 expression levels in ameloblasts. Expression levels of ClC-5 and ClC-7 (A) mRNA and (B) protein were determined in control and high fluoride treated cells. Data are presented as the mean \pm the standard deviation of three repeated experiments. ${ }^{*} \mathrm{P}<0.05$, ${ }^{* *} \mathrm{P}<0.01$ vs. control. TGF- $\beta 1$, transforming growth factor- $\beta 1$; ClC-5, voltage-gated chloride channel 5 ; ClC-7, voltage-gated chloride channel 7. 

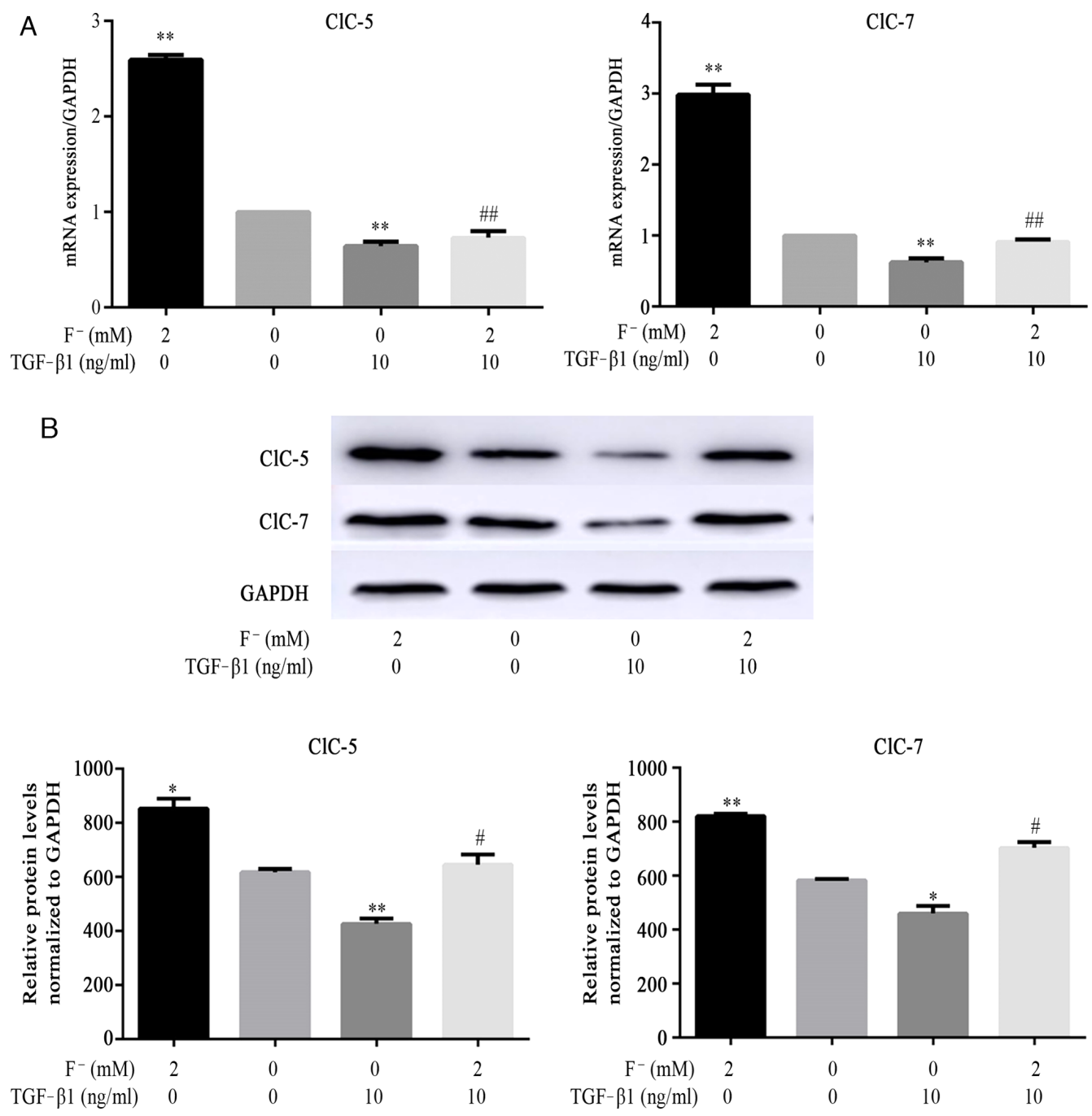

Figure 3. Effects of TGF- $\beta 1$ on ClC-5 and ClC-7 expression levels in ameloblasts. (A) mRNA and (B) protein levels of ClC-5 and ClC-7 in ameloblasts following treatment with high or low levels of fluoride and exogenous TGF- $\beta 1$ or a control. ${ }^{*} \mathrm{P}<0.05,{ }^{* *} \mathrm{P}<0.01$ vs. $0 \mathrm{~F}+0$ TGF- $\beta 1$; ${ }^{~} \mathrm{P}<0.05$, ${ }^{\# \#} \mathrm{P}<0.01$ vs. high fluoride. TGF- $\beta 1$, transforming growth factor- $\beta 1$; ClC-5, voltage-gated chloride channel 5 ; ClC-7, voltage-gated chloride channel 7.

than those of the high fluoride group. Fig. 3B illustrates the relative values (compared with the internal reference GAPDH) of $\mathrm{ClC}-5$ and $\mathrm{ClC}-7$ protein expression. In the high fluoride group, ClC-5 protein expression was higher than that of the control group. In the exogenous TGF- $\beta 1$ group, $\mathrm{ClC}-5$ protein expression was significantly lower than that of the control group. In the FT group, ClC-5 protein expression was lower than that of the high fluoride group. In those in the high fluoride group, $\mathrm{ClC}-7$ protein expression levels were significantly higher than that of the control group. In the exogenous TGF- $\beta 1$ group, $\mathrm{ClC}-7$ protein expression levels were lower than those of the control group. In the FT group, ClC-7 protein expression levels were lower than those of the high fluoride group.

Exogenous TGF- $\beta 1$ decreased the fluorescence intensity of LS8 cells. Fig. 4 demonstrates the fluorescence intensity of LS8 cells exposed to different treatments. The fluorescence intensity of the high fluoride group was significantly higher than that of the control group. The fluorescence intensity of the exogenous TGF- $\beta 1$ group was significantly lower than that of the control group. In the FT group, the fluorescence intensity was significantly lower than that of the high fluoride group.

\section{Discussion}

The results of the present study indicated that a high extracellular fluoride concentration had two effects on ameloblasts, an increase in intracellular fluoride concentration and an increase in $\mathrm{ClC}-5$ and $\mathrm{ClC}-7$ expression. Using probe 1, the red fluorescence intensity of intracellular fluoride in the high fluoride group was indicated to be stronger than that in the control group. Fluoride cannot enter ameloblasts directly and must be converted to HF beforehand (8). Protons are released during the process of hydroxyapatite (HA) deposition. Depending on the phosphate precursor, the precipitation of HA releases 8-14 moles of hydrogen ions per mole of HA, which acidifies the enamel matrix $(8,13,50)$. Additionally, a number of in vitro and in vivo studies have proved that fluoride can accelerate crystal formation and induce hypermineralized lines in secretory enamel $(51,52)$. Crystal growth produces a large number of protons, which can acidify the microenvironment (53). The low $\mathrm{pH}$ of the microenvironment promotes the conversion of fluoride to HF. According to the Henderson-Hasselbalch equation, more than 25 -fold the amount of HF is produced at $\mathrm{pH} 6.0$, compared with that at $\mathrm{pH} 7.4(8,13)$. Owing to the 
A

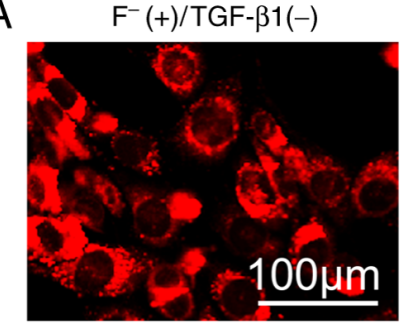

$\mathrm{F}^{-}(-) /$TGF- $\beta 1(-)$

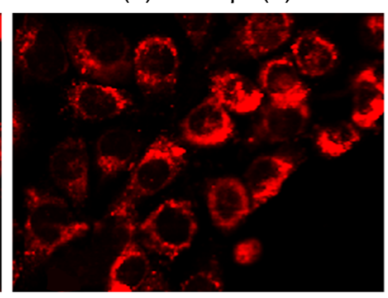

$\mathrm{F}^{-}(-) / \mathrm{TGF}-\beta 1(+)$

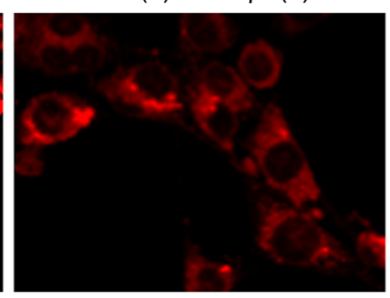

$\mathrm{F}^{-}(+) /$TGF- $\beta 1(+)$

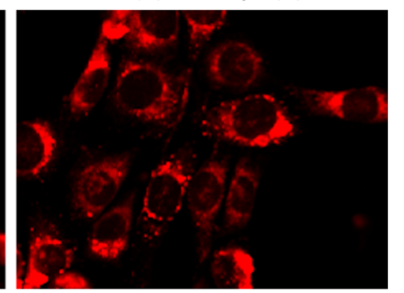

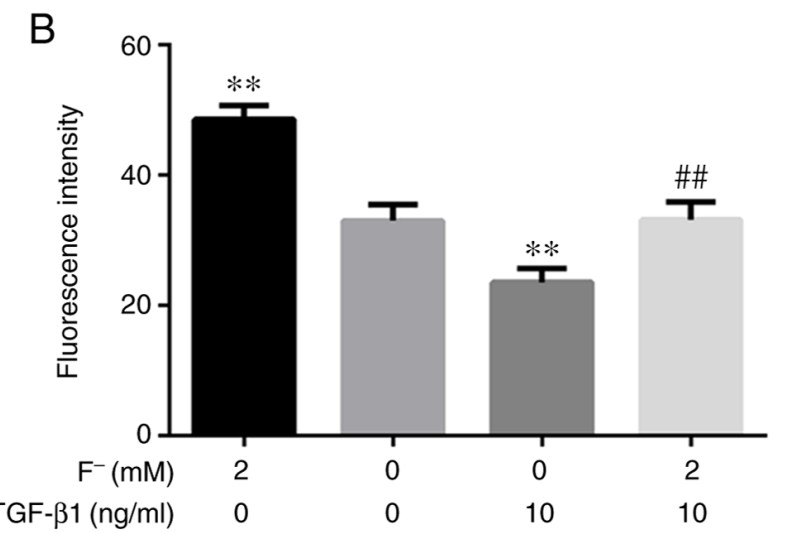

Figure 4. Effects of TGF- $\beta 1$ on fluorescence intensity in ameloblasts. (A)Fluorescence images and (B) intensities of probe 1 in ameloblasts following treatment with high or low levels of fluoride and exogenous TGF- $\beta 1$ or a control. . TGF- $\beta 1$, transforming growth factor- $\beta 1 ;{ }^{* *} \mathrm{P}<0.01$ vs. control; ${ }^{\# \#} \mathrm{P}<0.01$ vs. the high fluoride group.

$\mathrm{pH}$ gradient, HF may diffuse easily into the cytoplasm from the enamel matrix and revert to fluoride ions in the neutral cytoplasm; consequently, it cannot easily diffuse out of the cell $(8,9,13,16)$. Increased fluoride concentrations in the cytoplasm may induce oxidative stress and endoplasmic reticulum stress, both of which increase the occurrence of dental fluorosis $(8,10-12,14,15)$.

In the present study, probe 1 was employed to determine the intracellular fluoride concentration. Probe 1 is a highly selective ratiometric visual and red-emitting fluorescent dual-channel probe, which can detect fluoride in aqueous solution and living systems (49). In comparison to conventional technology, a ratiometric probe could eliminate most or all ambiguities by self-calibration at two wavelength intensities, which may avoid interference due to instrumental stability, sample environments and probe distribution $(17,21,49,54)$. Additionally, a ratiometric probe may display a large wavelength shift $(158 \mathrm{~nm})$ for practical use in ratiometric determination. The $158 \mathrm{~nm}$ shift caused by fluoride changes the solution containing probe 1 from yellow to blue (49). Thus probe 1 may serve as a visual probe for fluoride because it can be used to determine fluoride level changes by the naked-eye (49). Additionally, probe 1 could detect fluoride levels on the fluorescence spectrum, due to considerable fluorescence enhancement at $612 \mathrm{~nm}$ caused by the addition of fluoride (49). Furthermore, the probe 1 is a rapid analytical method for the detection of fluoride. Previous research suggested that the fluorescence intensity at $612 \mathrm{~nm}$ increased with reaction time and then leveled off at a reaction time $>\sim 25 \mathrm{~min}$ (49), which made probe 1 use easier. On the basis of this finding 30 min was chosen as the time point to assess the fluorescence intensity of fluoride using probe 1 in the present study.

The second effect of fluoride on ameloblasts an increase in $\mathrm{ClC}-5$ and $\mathrm{ClC}-7$ expression. As voltage-gated chloride channels, ClC-5 and ClC-7 are responsible for exchanging $\mathrm{Cl}^{-}$ and $\mathrm{H}^{+}$to maintain cell acidification. High expression levels of ClC-5 promote the influx of fluoride into the cytoplasm. ClC-7 localizes in vesicles of the endocytotic-lysosomal pathway in different cell types (30). It has been indicated that during the maturation stage of ameloblasts, the highest levels of ClC-7 are localized in ameloblast vesicles $(33,55)$. Thus, the high expression of $\mathrm{ClC}-7$ promotes the influx of fluoride into the endosome/lysosome. This may induce toxicity in ameloblasts, thereby leading to dental fluorosis $(8,13)$. CFTR stimulates the transport activity of Slc26a members, which leads to bicarbonate efflux $(37,56,57)$. Additionally, CFTR is permeable to bicarbonate $(37,58,59)$. Although the results of previous studies have indicated that CFTR is more permeable to $\mathrm{Cl}^{-}$than to bicarbonate, studies have revealed that CFTR may be responsible for more than $50 \%$ of the total bicarbonate efflux in pancreatic duct cells $(37,53,58)$. The low $\mathrm{pH}$ caused by HA deposition may lead to an increase in expression of the electrolyte transporter responsible for the efflux of bicarbonate $(60,61)$. The released bicarbonate may neutralize protons to produce a microenvironment that favors crystal nucleation. However, in the present study, no significant changes in CFTR were identified. This may be due to the use of different cell types or low expression of CFTR in LS8 cells. Further research is needed to better understand the mechanism underlying CFTR expression. Duan et al (38) found that excess fluoride inhibited endocytic activity of ameloblasts through the CFTR chloride channel or other chloride channels. CFTR siRNA and CFTR-specific channel inhibitor were employed to disturb the function of CFTR, which could examine the effects on the transport activity in presence of fluoride (38). Thus, future work will assess the effects of ClCs inhibitors 
or silencing with siRNAs on the expression and transport activity of ameloblasts.

TGF- $\beta 1$ is distributed in most cells and is activated through the release of latency-associated protein 1 and latent TGF- $\beta$-binding protein 1 (62-64). Active TGF- $\beta 1$ may activate and affect organic homeostasis by binding to the transforming growth factor- $\beta$ receptor 1 (TGF- $\beta$ R 1$)$ through the TGF- $\beta 1$-Smad signal pathway. Previous studies have shown that fluoride may repress the expression of TGF- $\beta 1(13,41,65,66)$ and the present study confirmed this result. In the present study, fluoride significantly reduced the expression levels of TGF- $\beta 1$ in ameloblasts at the gene and protein levels. TGF- $\beta 1$ may also impair the expression and function of chloride ion channels in other epithelial cells, including alveolar, bronchial, vas deferens and nasal polyp epithelial cells (43-46). To investigate the relationship between TGF- $\beta 1$ and chloride ion channels, exogenous TGF- $\beta 1$ was added to the culture medium. The present results suggested a largely negative correlation between them. Exogenous TGF- $\beta 1$ significantly reduced the expression levels of $\mathrm{ClC}-5$ and $\mathrm{ClC}-7$ in comparison with a control. When TGF- $\beta 1$ and high fluoride levels were added to the medium at the same time, the increase in the expression levels of $\mathrm{ClC}-5$ and $\mathrm{ClC}-7$ caused by fluoride was markedly reduced compared with high fluoride treatment alone. These results suggested that the addition of exogenous TGF- $\beta 1$ may compensate for the changes in $\mathrm{ClC}-5$ and $\mathrm{ClC}-7$ caused by the decrease of endogenous TGF- $\beta 1$ induced by fluoride. With the inhibition of ClC-5 and ClC-7 expression, the red fluorescence intensity of intracellular fluoride was weaker compared with that of the control group.

Both the decreased $\mathrm{pH}$ and the highly expressed $\mathrm{ClC}-5$ and $\mathrm{ClC}-7$ levels caused by the high fluoride concentration accelerated the accumulation of fluoride in ameloblasts. If the buffering capacity of ameloblasts is overwhelmed by an excessive amount of fluoride, hypomineralization occurs and may cause dental fluorosis. The present study may provide a new perspective for the prevention of dental fluorosis through TGF- $\beta$-mediated reduction of fluoride accumulation. The present study assessed the effect of exogenous TGF- $\beta 1$ on preventing the inflow of fluoride to ameloblasts through regulation of $\mathrm{ClC}-5$ and $\mathrm{ClC}-7$ for $24 \mathrm{~h}$. A longer time course will be utilized in future studies. Additionally, further studies are required to investigate the precise mechanism by which the ions are transported. Studies will also be conducted to confirm this hypothesis in vivo.

In conclusion, with the use of probe 1 , it was demonstrated that exogenous TGF- $\beta 1$ may prevent the accumulation of intracellular fluoride through the regulation of $\mathrm{ClC}-5$ and $\mathrm{ClC}-7$ in ameloblasts under high extracellular fluoride concentrations.

\section{Acknowledgements}

The authors would like to thank Professor Malcolm L. Snead (University of Southern California, USA) and Professor Baocun Zhu (Jinan University, Shandong, China) for kindly donating LS8 cells and probe 1 respectively.

\section{Funding}

No funding was received.

\section{Availability of data and materials}

The datasets used and/or analyzed during the current study are available from the corresponding author on reasonable request.

\section{Authors' contributions}

DZ and XD contributed to the conception and design of the present study. MJ, XH and JS conducted all the experiments. $\mathrm{MJ}$ and XD drafted the manuscript and revised it critically for important intellectual content. MJ, XH and JS interpreted and analyzed the data. MJ and XH were responsible for assessing the authenticity of all the raw data. All authors read and approve the final manuscript.

\section{Ethics approval and consent to participate}

Not applicable.

\section{Patient consent for publication}

Not applicable.

\section{Competing interests}

The authors declare that they have no competing interests.

\section{References}

1. Truman BI, Gooch BF, Sulemana I, Gift HC, Horowitz AM, Evans CA, Griffin SO, Carande-Kulis VG and Task Force on Community Preventive Services: Reviews of evidence on interventions to prevent dental caries, oral and pharyngeal cancers, and sports-related craniofacial injuries. Am J Prev Med 23 (Suppl 1): S21-S54, 2002.

2. Dean T, Jay P, Arnold F and Elvove E: Domestic water and dental caries. II. A study of 2832 white children, aged $12-14$ years, of 8 suburban communities, including Lactobacillus acidophilus studies of 1761 children. Public Health Reports 56: 761-792, 1941.

3. Denbesten P and Li W: Chronic fluoride toxicity: Dental fluorosis. Monogr Oral Sci 22: 81-96, 2011.

4. Institute of Medicine: Dietary reference intakes for calcium, phosphorus, magnesium, Vitamin D, and Fluoride. National Academies Press, Washington, DC, 1997.

5. Beltrán-Aguilar ED, Barker LK, Canto MT, Dye BA, Gooch BF, Griffin SO, Hyman J, Jaramillo F, Kingman A, Nowjack-Raymer R, et al: Surveillance for dental caries, dental sealants, tooth retention, edentulism, and enamel fluorosis-United States, 1988-1994 and 1999-2002. MMWR Surveill Summ 54: $1-43,2005$.

6. Bawden JW, Crenshaw MA, Wright JT and LeGeros RZ: Consideration of possible biologic mechanisms of fluorosis. J Dent Res 74: 1349-1352, 1995.

7. Robinson C, Connell S, Kirkham J, Brookes SJ, Shore RC and Smith AM: The effect of fluoride on the developing tooth. Caries Res 38: 268-276, 2004.

8. Sierant ML and Bartlett JD: Stress response pathways in ameloblasts: Implications for amelogenesis and dental fluorosis. Cells 1: 631-645, 2012.

9. Kawase T and Suzuki A: Studies on the transmembrane migration of fluoride and its effects on proliferation of L-929 fibroblasts (L cells) in vitro. Arch Oral Biol 34: 103-107, 1989.

10. Mittal $\mathrm{M}$ and Flora SJ: Effects of individual and combined exposure to sodium arsenite and sodium fluoride on tissue oxidative stress, arsenic and fluoride levels in male mice. Chem Biol Interact 162: 128-139, 2006.

11. Jin XQ, Xu H, Shi HY,Zhang JM and Zhang HQ: Fluoride-induced oxidative stress of osteoblasts and protective effects of baicalein against fluoride toxicity. Biol Trace Elem Res 116: 81-89, 2007. 
12. Varol E, Icli A, Aksoy F, Bas HA, Sutcu R, Ersoy IH, Varol S and Ozaydin M: Evaluation of total oxidative status and total antioxidant capacity in patients with endemic fluorosis. Toxicol Ind Health 29: 175-180, 2013

13. Sharma R, Tsuchiya M, Skobe Z, Tannous BA and Bartlett JD: The acid test of fluoride: How $\mathrm{pH}$ modulates toxicity. PLoS One 5: e10895, 2010.

14. Sharma R, Tsuchiya M and Bartlett JD: Fluoride induces endoplasmic reticulum stress and inhibits protein synthesis and secretion. Environ Health Perspect 116: 1142-1146, 2008.

15. Kubota K, Lee DH, Tsuchiya M, Young CS, Everett ET, Martinez-Mier EA, Snead ML, Nguyen L, Urano F and Bartlett JD: Fluoride induces endoplasmic reticulum stress in ameloblasts responsible for dental enamel formation. J Biol Chem 280: 23194-23202, 2005.

16. He H, Ganapathy V, Isales CM and Whitford GM: pH-dependent fluoride transport in intestinal brush border membrane vesicles. Biochim Biophys Acta 1372: 244-254, 1998.

17. Jiao Y, Zhu B, Chen J and Duan X: Fluorescent sensing of fluoride in cellular system. Theranostics 5: 173-187, 2015.

18. Gai L, Chen H, Zhou B, Lu H, Lai G, Li Z and Shen Z: Ratiometric fluorescence chemodosimeters for fluoride anion based on pyrene excimer/monomer transformation. Chem Commun (Camb) 48 10721-10723, 2012.

19. Kim SY, Park J, Koh M, Park SB and Hong J: Fluorescent probe for detection of fluoride in water and bioimaging in A549 human lung carcinoma cells. Chem Commun (Camb) 21: 4735-4737, 2009.

20. Ke B, Chen W, Ni N, Cheng Y, Dai C, Dinh H and Wang B: A fluorescent probe for rapid aqueous fluoride detection and cell imaging. Chem Commun (Camb) 49: 2494-2496, 2013.

21. Li Y, Zhang X, Zhu B, Yan J and Xu W: A highly selective colorimetric and 'off-on-off' fluorescent probe for fluoride ions. Anal Sci 26: 1077-1080, 2010.

22. Zhu B, Yuan F, Li R, Li Y, Wei Q, Ma Z, Du B and Zhang X: A highly selective colorimetric and ratiometric fluorescent chemodosimeter for imaging fluoride ions in living cells. Chem Commun (Camb) 47: 7098-7100, 2011.

23. Dawson DC, Smith SS and Mansoura MK: CFTR: Mechanism of anion conduction. Physiol Rev 79 (Suppl 1): S47-S75, 1999.

24. Simchowitz L: Interactions of bromide, iodide, and fluoride with the pathways of chloride transport and diffusion in human neutrophils. J Gen Physiol 91: 835-860, 1988.

25. Ran S, Fuller CM, Arrate MP, Latorre R and Benos DJ: Functional reconstitution of a chloride channel protein from bovine trachea J Biol Chem 267: 20630-20637, 1992.

26. Duszyk M, Liu D, Kamosinska B, French AS and Man SF: Characterization and regulation of a chloride channel from bovine tracheal epithelium. J Physiol 489: 81-93, 1995.

27. Anderson M, Gregory RJ, Thompson S, Souza DW, Paul S, Mulligan RC, Smith AE and Welsh MJ: Demonstration that CFTR is a chloride channel by alteration of its anion selectivity. Science 253: 202-205, 1991.

28. Jentsch TJ, Stein V, Weinreich F and Zdebik AA: Molecular structure and physiological function of chloride channels. Physiol Rev 82: 503-568, 2002.

29. Stauber T, Weinert S and Jentsch TJ: Cell biology and physiology of CLC chloride channels and transporters. Compr Physiol 2 : 1701-1744, 2012

30. Duan X: Ion channels, channelopathies, and tooth formation. J Dent Res 93: 117-125, 2014

31. Hou J, Situ Z and Duan X: ClC chloride channels in tooth germ and odontoblast-like MDPC-23 cells. Arch Oral Biol 53: 874-878, 2008

32. Duan X, Mao Y, Yang T, Wen X, Wang H, Hou J, Xue Y and Zhang R: ClC-5 regulates dentin development through TGF-beta1 pathway. Arch Oral Biol 54: 1118-1124, 2009.

33. Lacruz RS, Brookes SJ, Wen X, Jimenez JM, Vikman S, Hu P, White SN, Lyngstadaas SP, Okamoto CT, Smith CE and Paine ML: Adaptor protein complex 2-mediated, clathrin-dependent endocytosis, and related gene activities, are a prominent feature during maturation stage amelogenesis. J Bone Miner Res 28: 672-687, 2013.

34. Wright JT, Kiefer CL, Hall KI and Grubb BR: Abnormal enamel development in a cystic fibrosis transgenic mouse model. J Dent Res 75: 966-973, 1996.

35. Lacruz RS, Smith CE, Moffatt P, Chang EH, Bromage TG, Bringas P Jr, Nanci A, Baniwal SK, Zabner J, Welsh MJ, et al: Requirements for ion and solute transport, and $\mathrm{pH}$ regulation during enamel maturation. J Cell Physiol 227: 1776-1785, 2012.
36. Sui $\mathrm{W}$, Boyd $\mathrm{C}$ and Wright JT: Altered $\mathrm{pH}$ regulation during enamel development in the cystic fibrosis mouse incisor. J Dent Res 82: 388-392, 2003.

37. Bronckers A, Kalogeraki L, Jorna HJ, Wilke M, Bervoets TJ, Lyaruu DM, Zandieh-Doulabi B, Denbesten P and de Jonge H: The cystic fibrosis transmembrane conductance regulator (CFTR) is expressed in maturation stage ameloblasts, odontoblasts and bone cells. Bone 46: 1188-1196, 2010.

38. Duan X, Mao Y, Wen X, Yang T and Xue Y: Excess fluoride interferes with chloride-channel-dependent endocytosis in ameloblasts. J Dent Res 90: 175-180, 2011.

39. Maeda H, Wada N, Tomokiyo A, Monnouchi S and Akamine A: Prospective potency of TGF- $\beta 1$ on maintenance and regeneration of periodontal tissue. Int Rev Cell Mol Biol 304: 283-367, 2013.

40. Zhao H, Oka K, Bringas P, Kaartinen V and Chai Y: TGF-beta type I receptor Alk5 regulates tooth initiation and mandible patterning in a type II receptor-independent manner. Dev Biol 320: 19-29, 2008.

41. Suzuki M, Shin M, Simmer JP and Bartlett JD: Fluoride affects enamel protein content via TGF- $\beta 1$-mediated KLK4 inhibition. J Dent Res 93: 1022-1027, 2014.

42. Den Besten PK: Mechanism and timing of fluoride effects on developing enamel. J Public Health Dent 59: 247-251, 1999.

43. Roux J, Carles M, Koh H, Goolaerts A, Ganter MT, Chesebro BB, Howard M, Houseman BT, Finkbeiner W, Shokat KM, et al: Transforming growth factor betal inhibits cystic fibrosis transmembrane conductance regulator-dependent cAMP-stimulated alveolar epithelial fluid transport via a phosphatidylinositol 3-kinase-dependent mechanism. J Biol Chem 285: 4278-4290, 2010.

44. Snodgrass SM, Cihil KM, Cornuet PK, Myerburg MM and Swiatecka-Urban A: Tgf- $\beta 1$ inhibits Cftr biogenesis and prevents functional rescue of $\triangle \mathrm{F} 508$-Cftr in primary differentiated human bronchial epithelial cells. PLoS One 8: e63167, 2013

45. Yi S, Pierucci-Alves F and Schultz BD: Transforming growth factor- $\beta 1$ impairs CFTR-mediated anion secretion across cultured porcine vas deferens epithelial monolayer via the p38 MAPK pathway. Am J Physiol Cell Physiol 305: C867-C876, 2013.

46. Pruliere-Escabasse V, Fanen P, Dazy AC, Lechapt-Zalcman E, Rideau D, Edelman A, Escudier E and Coste A: TGF-beta 1 downregulates CFTR expression and function in nasal polyps of non-CF patients. Am J Physiol Lung Cell Mol Physiol 288: L77-L83, 2005

47. Faibish D, Suzuki M and Bartlett JD: Appropriate real-time PCR reference genes for fluoride treatment studies performed in vitro or in vivo. Arch Oral Biol 62: 33-42, 2016.

48. Livak KJ and Schmittgen TD: Analysis of relative gene expression data using real-time quantitative PCR and the 2(-Delta Delta C(T)) method. Methods 25: 402-408, 2001.

49. Zhu B, Kan H, Liu J, Liu H, Wei Q and Du B: A highly selective ratiometric visual and red-emitting fluorescent dual-channel probe for imaging fluoride anions in living cells. Biosens Bioelectron 52: 298-303, 2014

50. Smith CE, Chong DL, Bartlett JD and Margolis HC: Mineral acquisition rates in developing enamel on maxillary and mandibular incisors of rats and mice: Implications to extracellular acid loading as apatite crystals mature. J Bone Miner Res 20: 240-249, 2005

51. Lyaruu DM, Medina JF, Sarvide S, Bervoets TJ, Everts V, Denbesten P, Smith CE and Bronckers AL: Barrier formation: Potential molecular mechanism of enamel fluorosis. J Dent Res 93: 96-102, 2014.

52. Bronckers AL, Lyaruu DM, Jansen ID, Medina JF, Kellokumpu S, Hoeben KA, Gawenis LR, Oude-Elferink RP and Everts V: Localization and function of the anion exchanger Ae2 in developing teeth and orofacial bone in rodents. J Exp Zool B Mol Dev Evol 312B: 375-387, 2009.

53. Ji M, Xiao L, Xu L, Huang $\mathrm{S}$ and Zhang D: How $\mathrm{pH}$ is regulated during amelogenesis in dental fluorosis. Exp Ther Med 16: 3759-3765, 2018

54. Fan J, Hu M, Zhan P and Peng X: Energy transfer cassettes based on organic fluorophores: Construction and applications in ratiometric sensing. Chem Soc Rev 42: 29-43, 2013.

55. Leisle L, Ludwig CF, Wagner FA, Jentsch TJ and Stauber T: ClC-7 is a slowly voltage-gated $2 \mathrm{Cl}(-) / 1 \mathrm{H}(+)$-exchanger and requires Ostm1 for transport activity. EMBO J 30: 2140-2152, 2011.

56. Ko SB, Zeng W, Dorwart MR, Luo X, Kim KH, Millen L, Goto H, Naruse S, Soyombo A, Thomas PJ and Muallem S: Gating of CFTR by the STAS domain of SLC26 transporters. Nat Cell Biol 6: 343-350, 2004 
57. Mount DB and Romero MF: The SLC26 gene family of multifunctional anion exchangers. Pflugers Arch 447: 710-721, 2004.

58. Ishiguro H, Steward MC, Naruse S, Ko SB, Goto H, Case RM, Kondo T and Yamamoto A: CFTR functions as a bicarbonate channel in pancreatic duct cells. J Gen Physiol 133: 315-326, 2009.

59. Shcheynikov N, Kim KH, Kim KM, Dorwart MR, Ko SB, Goto H Naruse S, Thomas PJ and Muallem S: Dynamic control of cystic fibrosis transmembrane conductance regulator $\mathrm{Cl}(-) / \mathrm{HCO} 3(-)$ selectivity by external Cl(-). J Biol Chem 279: 21857-21865, 2004.

60. Paine ML, Snead ML, Wang HJ, Abuladze N, Pushkin A, Liu W, Kao LY, Wall SM, Kim YH and Kurtz I: Role of NBCe1 and AE2 in secretory ameloblasts. J Dent Res 87: 391-395, 2008.

61. Zheng L, Zhang Y, He P, Kim J, Schneider R, Bronckers AL, Lyaruu DM and DenBesten PK: NBCe1 in mouse and human ameloblasts may be indirectly regulated by fluoride. J Dent Res 90: 782-787, 2011.

62. Lawrence DA, Pircher R and Jullien P: Conversion of a high molecular weight latent beta-TGF from chicken embryo fibroblasts into a low molecular weight active beta-TGF under acidic conditions. Biochem Biophys Res Commun 133: 1026-1034, 1985.
63. Munger JS, Harpel JG, Gleizes PE, Mazzieri R, Nunes I and Rifkin DB: Latent transforming growth factor-beta: Structural features and mechanisms of activation. Kidney Int 51: 1376-1382, 1997.

64. Oklu R and Hesketh R: The latent transforming growth factor beta binding protein (LTBP) family. Biochem J 352 Pt 3: 601-610, 2000.

65. Suzuki M, Everett ET, Whitford GM and Bartlett JD: 4-phenylbutyrate mitigates fluoride-induced cytotoxicity in ALC cells. Front Physiol 8: 302, 2017.

66. Zhang X, Zhang Y, Xi S, Cheng G and Guo X: The effect of different fluoride concentrations on the expression of transforming growth factor-betal in ameloblast of rat incisor. Hua $\mathrm{X}$ Kou Qiang Yi Xue Za Zhi 30: 434-438, 2012 (In Chinese).

This work is licensed under a Creative Commons Attribution-NonCommercial-NoDerivatives 4.0 International (CC BY-NC-ND 4.0) License. 